\title{
PEMBELAJARAN PAI DENGAN PENDEKATAN INTEGRATIF PADA MASA PANDEMI COVID-19 DI SD PTQ ANNIDA SALATIGA
}

\author{
Ahmad Fikri Sabiq \\ Institut Agama Islam Negeri (IAIN) Salatiga, Jawa Tengah \\ ahmadfikrisabiq@gmail.com
}

DOI : http://doi.org/10.37730/edutrained.v5i1.132

Diterima: 22 Maret 2021 | Disetujui: 2 Juli 2021 | Dipublikasikan: 6 Juli 2021

\begin{abstract}
Abstrak
Tujuan dari penelitian ini adalah untuk mengetahui bagaimana pelaksanaan pembelajaran Pendidikan Agama Islam yang terintegratif secara menyeluruh di satuan pendidikan. Penelitian ini merupakan penelitian lapangan dengan pendekatan kualitatif. Penelitian dilaksanakan pada bulan Januari-Maret 2021 di SD Plus Tahfizhul Quran (PTQ) Annida, Salatiga. Teknik pengumpulan data dengan observasi, wawancara, dan dokumentasi. Analisis data dilakukan dengan penyajian, reduksi, dan penarikan kesimpulan. Pelaksanaan pembelajaran PAI secara integratif ini meliputi program yang ada di sekolah dan kerjasama dengan orang tua di rumah. Aspek dari pembelajaran PAI secara integratif langsung di SD Plus Tahfizhul Quran (PTQ) ANNIDA Al-Qur'an, fiqih dan akhlak. Materi AlQur'an meliputi pembiasaan Baca Tulis Al-Quran dan menghafalkan Al-Quran. Materi fiqih meliputi shalat dhuha, shalat dzuhur dan ashar secara berjamaah. Sedangkan materi akhlak adalah pembiasaan toleransi, bersimpati, hormat kepada orang tua, hormat kepada guru, dan tolong menolong. Hasil dari pembelajaran PAI integratif ini adalah lebih dari 75\% anak-anak melaksanakan shalat dengan tertib, pembiasaan shalat sunah dan berjama'ah, kemampuan mengaji dan hafalan AlQur'an, pembiasaan positif di rumah, serta sikap empati dan simpati dari anak-anak. Kendala yang muncul adalah guru tidak bisa memantau secara penuh karena siswa tidak berangkat ke sekolah, siswa kurang semangat, dan komunikasi yang kurang maksimal. Solusi yang dihadirkan adalah menyederhanakan instruksi pembelajaran oleh guru, menjalin komunikasi sebaik mungkin, dan pemberian apresiasi kepada siswa agar tambah semangat.
\end{abstract}

Kata Kunci: Pembelajaran, Pendidikan Agama Islam, Pendekatan Integratif

\begin{abstract}
The purpose of this study was to find out how the implementation of integrated Islamic Religious Education learning in the education unit was comprehensive. This research is a field research with a qualitative approach. The research was conducted in January-March 2021 at SD Plus Tahfizhul Quran (PTQ) Annida, Salatiga. Data collection techniques by observation, interviews, and documentation. Data analysis was carried out by presenting, reducing, and drawing conclusions. The implementation of integrated PAI learning includes existing programs at school and collaboration with parents at home. Aspects of integrated PAI learning directly at SD Plus Tahfizhul Quran (PTQ) ANNIDA Al-Qur'an, figh and morals. The material of the Qur'an includes the habit of reading and writing the Qur'an and memorizing the Qur'an. Fiqh material includes dhuha prayer, midday prayer and asr prayer in congregation. While the moral material is the habit of tolerance, sympathy, respect for parents, respect for teachers, and help. The results of this integrative PAI learning are that more than $75 \%$ of children pray in an orderly manner, habituation of sunnah and congregational prayers, the ability to recite and memorize the Qur'an, positive habits at home, as well as empathy and sympathy from children. child. The obstacles that arise are that teachers cannot monitor fully because students do not go to school, students are less enthusiastic, and communication is not optimal. The solution presented is to simplify learning instructions by the teacher, establish the best possible communication, and give appreciation to students to increase their enthusiasm.
\end{abstract}

Keywords: Learning, Islamic Education, Integration Approach 


\section{PENDAHULUAN}

Dalam kurikulum pendidikan nasional, mata pelajaran Pendidikan Agama Islam (PAI) menjadi mata pelajaran wajib yang ada di sekolah. Mata pelajaran ini diharapkan bisa menumbuhkan sikap religius siswa, menambah wawasan keagamaan, serta meningkatkan keimanan dan ketakwaan kepada Allah Swt. Hal ini sesuai dengan cita-cita bangsa Indonesia yakni bangsa yang beriman dan bertakwa terhadap Tuhan Yang Maha Esa. Hal ini sesuai dengan UU Sistem Pendidikan Nasional (Sisdiknas) Nomor 20 Tahun 2003.

Sentuhan PAI dalam konteks pembentukan karakter sangat kuat dan strategis. PAI yang berisikan nilai normatif dan sosiologis mendapat porsi yang kuat dalam pembangunan nasional. Kementerian agama sebagai salah satu instansi pemerintah, berdasarkan PP 55 tahun 2007 tentang Pendidikan Agama dan Keagamaan, memiliki posisi strategis dalam meningkatkan mutu pendidikan karakter bangsa, yang dalam hal ini dilaksanakan oleh Direktorat PAI, di bawah naungan Ditjen Pendidikan Islam (Suryadi, 2016:23-276)..

Sebagaimana dikutip oleh Sunhaji, Mochtar Buchori menyatakan bahwa mata pelajaran Pendidikan Agama Islam (PAI) dinilai masih gagal dalam memaksimalkan peran strategisnya sebagai pelajaran yang lebih dekat dengan kehidupan. Kegagalan ini, menurutnya, disebabkan karena praktik pendidikannya yang lebih banyak memperhatikan aspek kognitif dan mengabaikan proses yang mengarah ke aspek afektif (Sunhaji, 2014:334-358).

Abudin Nata dalam Wage dan Sulaeman menyebutkan bahwa kurang efektifnya pendidikan agama di sekolah dikarenakan pendidikan agama terkesan hanya menjadi bahan hafalan dan wacana, belum menjadi pegangan hidup. Agama baru dimiliki dan belum menjadi pandangan sublimatif dan transformatif ke dalam hati, pikiran, dan perilaku manusia sebagai pemeluknya (Wage dan Sulaeman, 2016:31-40).
Lebih lanjut, Komaruddin Hidayat menyebutkan mata pelajaran PAI lebih banyak berorientasi pada belajar tentang agama Islam, sehingga hasilnya banyak orang yang mengetahui nilai-nilai ajaran agama, tetapi perilakunya tidak relevan dengan nilai-nilai ajaran agama yang diketahuinya (Hidayat, 1999:7). Amin Abdullah juga menyatakan bahwa pendidikan agama lebih banyak terkonsentrasi pada persoalan-persoalan teoritis keagamaan yang bersifat kognitif, dan kurang fokus terhadap persoalan cara mengubah pengetahuan agama yang kognitif menjadi makna dan nilai yang perlu diinternalisasikan dalam diri peserta didik lewat berbagai cara, media, dan forum (Abdullah, 2003:18).

Lebih lanjut, Suryadi menyebutkan bahwa dalam konteks pembelajaran, terdapat beberapa masalah yang muncul dalam PAI di antaranya yaitu: 1) guru PAI lebih terkonsentrasi pada persoalan teoritis keilmuan yang bersifat kognitif semata dan lebih menekankan pada pekerjaan mengajar/transfer ilmu; 2) Metodologi pembelajaran PAI selama ini secara umum monoton sehingga cenderung membosankan peserta didik; 3) Pelajaran PAI seringkali dilaksanakan di sekolah bersifat menyendiri, kurang terintegrasi dengan bidang studi yang lain; 4) Pembelajaran PAI seringkali terkonsentrasi dalam kelas dan enggan untuk dilakukan kegiatan praktek dan penelitian di luar kelas; 5) Penggunaan media pembelajaran baik yang dilakukan guru maupun peserta didik kurang kreatif, variatif dan menyenangkan.; 6) Pembelajaran PAI cenderung normatif, linier, tanpa ilustrasi konteks sosial budaya; dan 7) Kurang adanya komunikasi dan kerjasama dengan orang tua dalam menangani permasalahan peserta didik (Suryadi, 2016:253-276)

Selanjutnya, menurut Soedjatmoko dalam Sunhaji menyatakan bahwa pendidikan agama harus berusaha berintegrasi dan bersinkronisasi dengan pendidikan non-agama. Pendidikan agama tidak boleh dan tidak dapat berjalan sendiri, tetapi harus sinergi dengan program-program pendidikan 
non-agama agar mempunyai relevansi terhadap perubahan sosial yang terjadi di masyarakat, tanpa sinergi dengan mata pelajaran lain seperti sains, pengetahuan peserta didik hanya terbatas pada aspek nilai-nilai keagamaan saja (Sunhaji, 2014:334-358).

Sekolah sebagai salah satu institusi pendidikan memerlukan banyak instrumen pendukung seperti kepentingan dan kualitas yang baik dari kepala sekolah dan guru, peran aktif pihak pemerintah melalui dinas pendidikan, peran aktif orang tua dan masyarakat. Terbentuknya kerjasama antara guru, orang tua, dan masyarakat sesuai dengan perannya masing masing, akan mewujudkan suatu pembelajaran PAI yang integratif. Sebab mereka itu memiliki kontribusi dalam keberhasilan proses pembelajaran PAI (Irwan, 2020:55-68).

Melihat realita tersebut, penulis berpendapat harus ada internalisasi Pendidikan Agama Islam dari teori (kognitif) dan praktik (afektif) agar terwujud hasil sesuai dengan yang diharapkan. Internalisasi ini dilakukan dengan mewujudkan pembelajaran agama yang terintegrasi dengan kehidupan siswa baik di sekolah dan di rumah.

Bertitik tolak dari pemikiran di atas dan didasari kebutuhan untuk memberikan penekanan yang lebih kuat pada pendidikan yang dapat mengembangkan kualitas siswa, maka upaya pembinaan keimanan dan ketakwaan siswa perlu dilakukan perluasan dan pengayaan, tidak lagi cukup hanya didekati secara monolitik, melainkan integratif. Artinya, pembinaan keimanan dan ketakwaan tidak lagi dipercayakan kepada PAI sebagai suatu mata pelajaran, melainkan dikembangkan strategi lain secara komplementer. Bersamaan dengan itu dikotomi yang selama ini terjadi antara pendidikan agama dengan pendidikan umum mulai perlu dijembatani (Sunhaji, 2014:334358).

Apalagi mata pelajaran yang berkenaan dengan penanaman karakter harus lebih berupa kontekstual, terkhusus lagi pada jenjang pendidikan Islam, di semua tingkatan (Madrasah Ibtidaiyah, Madrasah Tsanawiyah, Madrasah Aliyah) satu mata pelajaran khusus terkait pembinaan karakter, yaitu Akidah Akhlak. Selain itu, pendidikan Islam harus menomorsatukan sikap/ moral dari pada intelektual dan tidak ada kegiatan yang lebih didahului oleh afektifitasasi keimanan kepada Tuhan (Siddik, 2011:49).

Di tengah situasi pandemi Covid-19 yang berdampak ke bidang pendidikan sejak Maret 2020, mengharuskan pembelajaran dilaksanakan secara jarak jauh. Para pelaku pendidikan harus berpikir kreatif serta bertindak cepat dan tepat agar proses pendidikan dan pembelajaran tetap berjalan dengan baik. Termasuknya pelajaran Pendidikan Agama Islam (PAI) juga harus tetap berjalan serta memiliki hasil positif bagi peserta didik. Sebagaimana disampaikan sebelumnya bahwa pendidikan PAI tidak hanya berorientasi pada aspek kognitif, begitupun di tengah pandemi Covid-19 ini. Oleh karenanya, diperlukan strategi khusus untuk mencapai hal tersebut.

SD Plus Tahfizhul Quran (PTQ) Annida Salatiga merupakan satu dari ribuan sekolah di Indonesia yang melaksanakan pembelajaran jarak jauh. Di sekolah ini, Pendidikan Agama Islam tidak hanya mencakup materi kompetensi dasar yang dikeluarkan oleh pemerintah. Pembelajaran PAI di sekolah ini ditambah dengan pembentukan lingkungan yang mendukung adanya pelaksanaan pembelajaran PAI di luar kels, pengamalan ibadah sehari-hari, dan tambahan materi Al-Qur'an yang menjadi program khusus di sekolah ini. Semua materi tersebut dilaksanakan secara integratif baik di kelas, di luar kelas, dan di rumah melalui berbagai program. Strategi ini diharapkan bisa menjadikan pembelajaran PAI lebih relevan dengan realita dan tidak hanya berorientasi pada aspek kognitif. Terkhusus di tengah pandemi Covid-19 ini dimana pembelajaran dilaksanakan secara jarak jauh, tentu ada strategi khusus yang 
dilakukan oleh sekolah berkenaan dengan pembelajaran PAI secara integratif.

Berkenaan dengan penelitian ini, penulis akan meneliti tentang program pembelajaran PAI integratif yang ada di SD Plus Tahfizhul Quran (SD PTQ) ANNIDA Salatiga. Penulis berharap dari penyusunan tulisan ini bisa menjadi referensi dan role model yang bisa diterapkan oleh sekolah-sekolah dasar yang lain.

Dalam penelitian yang dilakukan oleh Harpan Reski Mulia, dipaparkan tentang integrasi pendidikan karakter dalam pembelajaran akidah akhlak. Dia membahas tentang model dan langkah yang dilakukan dalam proses pembelajaran sebagai bagian dari proses integrasi. Dia memfokuskan pembahasan pelajaran akidah akhlak dari aspek internalnya sendiri (Mulia, 2020:118129). Selanjutnya, dalam penelitian oleh Sunhaji, diuraikan tentang model pembelajaran integratif pendidikan agama Islam dan Sains. Dia mengangkat bagaimana tema-tema pada mata pelajaran PAI yang ada muatan sains ini dikaitkan dengan mata pelajaran umum seperti fisika, kimia, dan biologi (Sunhaji, 2014:334-358). Lukman Hakim, menguraikan tentang model integrasi pendidikan anti korupsi dalam kurikulum pendidikan Islam. Dia menguraikan nilainilai keislaman yang ada dalam pendidikan anti korupsi yang diintegrasikan ke dalam kurikulum pendidikan agama Islam.

Persamaan antara penelitian ini dengan penelitian di atas adalah samasama mengungkap tentang tema-tema yang diintegrasikan dengan mata pelajaran pendidikan agama Islam (PAI), seperti diintegrasikan dengan sains, nilai karakter anti korupsi, dan pembelajaran akidah di dalam kelas. Sedangkan yang menjadi pembeda dari penelitian ini adalah terletak pada hal yang diintegrasikan dengan mata pelajaran PAI, yaitu kegiatan atau pengamalanpengalaman keagamaan baik yang ada di sekolah ataupun di rumah.

\section{RUMUSAN MASALAH}

Rumusan masalah dari penelitian ini adalah: (1) bagaimana strategi pembelajaran PAI dengan pendekatan integratif? (2) bagaimana kendala dan solusi dalam pembelajaran PAI dengan pendekatan integratif di masa pandemi Covid-19?

\section{KAJIAN PUSTAKA}

Abuddin Nata menuturkan bahwa setidaknya ada delapan penyakit yang dijumpai pada masyarakat modern. Pertama, disintegrasi antar ilmu pengetahuan yang berakibat pada terjadinya pengkotak-kotakannya akal fikiran manusia dan cenderung membingungkan masyarakat. Kedua, kepribadian yang terpecah sebagai akibat dari kehidupan yang dipolakan oleh ilmu pengetahuan yang terlampau terspesialisasi dan tidak berwatak nilainilai ketuhanan. Ketiga, danfgkalnya rasa keimanan, ketakwaan, serta kemanusiaan sebagai akibat dari kehidupan yang terlampau rasionalistik dan individualistik. Keempat, timbulnya pola hubungan yang materialistik sebagai akibat dari kehidupan yang mengejar duniawi yang berlebihan. Kelima, cenderung menghalalkan segala cara, sebagai akibat dari faham hedonisme yang melanda kehidupan. Keenam, mudah stres dan frustasi, sebagai akibat dari terlalu percaya dan bangga terhadap kemampuan dirinya, tanpa dibarengi sikap tawakal dan percaya pada ketentuan Tuhan. Ketujuh, perasaan terasing di tengah-tengah keramaian sebagai akibat dari sikap individualistik. Kedelapan, kehilangan harga diri dan masa depannya sebagai akibat dari perbuatan yang menyimpang (Nata, 2007:82-82).

Mata pelajaran Pendidikan Agama Islam merupakan mata pelajaran wajib yang terdiri dari beberapa materi keagamaan. Materi keagamaan yang ada dalam PAI ini meliputi: Al-Quran, hadits, akidah, fikih, sejarah, akhlak, dan bahasa Arab. Kalau dalam sekolah di bawah 
naungan Kementerian Agama (Kemenag) seperti Madrasah Ibtidaiyah, Madrasah Tsanawiyah, dan Madrasah Aliyah, untuk mata pelajaran PAI terbagi menjadi lima mata pelajaran, yaitu: Al-Quran Hadits, Akidah Akhlak, Sejarah Kebudayaan Islam, Fikih, dan Bahasa Arab. Sedangkan pada sekolah di bawah Kementerian Pendidikan (Kemdikbud), lima mata pelajaran di atas masuk ke dalam satu mata pelajaran, yaitu mata pelajaran Pendidikan Agama Islam (PAI) dan kemudian ada tambahan Budi Pekerti.

Integratif memiliki arti pertama keseluruhan atau utuh, yang kedua berarti bersatunya antar bagian menjadi satu, yang ketiga berarti menghilangkan hambatan. Kaitannya dengan kegiatan pembelajaran, maka pembelajaran Integratif adalah bersatunya antara materi pelajaran dengan kegiatan secara keseluruhan di sekolah serta kerjasama sekolah dengan orang tua dalam upaya melaksanakan pengamalan-pengamalan PAI secara nyata di luar sekolah.

Integrasi adalah perpaduan menjadi satu kesatuan yang utuh antara dua pokok bahasan. Jadi yang disebut dengan kurikulum Pendidikan Agama Islam integratif adalah upaya perpaduan antara ilmu agama dan ilmu umum. Hal ini sesuai dengan Jaring Laba-laba Keilmuan yang ditawarkan oleh M. Amin Abdullah (Isnaeni, 2016:37-52).

Kurikulum sebagai salah satu komponen pendidikan perlu dikembangkan secara simultan dalam rangka merespon tantangan di masa depan, menawarkan salah satu bentuknya dengan mengayomi keberagaman anak dalam pembelajaran, yaitu kurikulum integrasi. Dalam bentuk ini, kurikulum terintegrasikan (tidak terpisah-pisah atau terpadu) antara satu metode dengan mata pelajaran lainnya sehingga peserta didik secara signifikan dapat meningkatkan pembelajarannya untuk kehidupan yang sangat penting di dalam masyarakat (Wiles, 2007:187188).

Oleh karena itu, diperlukan solusi terhadap kondisi PAI yang berlangsung di sekolah-sekolah

umum agar terselenggara dengan efektif dan efisien dengan melakukan perubahan dan perbaikan pendekatan serta pengembangan kurikulum. Sehingga apa yang dipelajari peserta didik dapat bermanfaat untuk diterapkan dalam kehidupan sehari-hari bukan menjadikannya asing di masyarakat dan merasa dirinya 'tercabut' dari lingkungannya (Isnaeni, 2016:37-52).

\section{METODE PENELITIAN}

Penelitian ini merupakan penelitian lapangan (field research) dengan pendekatan kualitatif. Penelitian dilaksanakan pada bulan Januari-Maret 2021 di SD Plus Tahfizhul Quran (PTQ) Annida, Salatiga. Teknik pengumpulan data adalah dengan observasi, wawancara, dan dokumentasi. Observasi ditujukan pada proses pembelajaran Pendidikan Agama Islam (PAI) di kelas. Wawancara ditujukan kepada kepala sekolah, guru pengampu mata pelajaran Pendidikan Agama Islam (PAI), dan wali kelas. Sedangkan dokumentasi ditujukan kepada dokumen-dokumen administrasi pembelajaran serta dokumen pendukung lainnya. Analisis data dilakukan dengan penyajian, reduksi, dan penarikan kesimpulan.

\section{PEMBAHASAN DAN HASIL PENELITIAN}

SD Plus Tahfizhul Quran (PTQ) ANNIDA merupakan sekolah tingkat dasar yang didirikan oleh Yayasan AnNida Salatiga. Secara kedinasan, sekolah ini di bawah naungan Dinas Pendidikan Kota Salatiga, dan lebih luas berada di bawah Kemdikbud. Oleh karena sekolah ini berada di bawah Dinas Pendidikan, sekolah ini mengikuti program kurikulum yang berlaku secara nasional sebagaimana SD pada umumnya.

Selain memberlakukan kurikulum yang berlaku secara nasional, Sekolah ini juga memiliki program tambahan, yaitu program menghafal Al Quran. Selama enam tahun, para siswa-siswi ditarget untuk bisa menghafalkan Al Quran 10 juz. Selain program tersebut, sekolah ini juga 
ada program-program pembiasaan ibadah, seperti shalat dhuha, berjamaah, dan lain sebagainya.

Di SD Plus Tahfizhul Quran (PTQ) ANNIDA ada beberapa materi dalam PAI yang diintegrasikan dalam programprogram di sekolah. Program-program yang diintegrasikan tersebut yaitu: Pertama, materi Al-Qur'an yang meliputi Baca Tulis Al-Quran (BTAQ) dan hafalan Al-Qur'an. Dalam kurikulum PAI, disebutkan tentang adanya materi-materi tentang memahami bacaan Al Quran. Di SD Plus Tahfizhul Quran (PTQ) Annida ini, pembelajaran materi tentang baca tulis $\mathrm{Al}$ Quran tidak hanya diajarkan di dalam jam pelajaran PAI namun juga diajarkan di luar itu, yaitu dilakukan setiap hari dari pukul 07.40-08.10 WIB. Selain itu, program penunjang PAI ini tidak hanya diajarkan oleh guru mata pelajaran PAI namun diajarkan oleh guru khusus baca tulis Al Quran.

Selanjutnya adalah menghafalkan ayat-ayat Al-Quran. Dalam kurikulum PAI, disebutkan tentang adanya materi-materi tentang menghafalkan ayat-ayat $\mathrm{Al}$ Quran. Di SD Plus Tahfizhul Quran (PTQ) Annida ini, pembelajaran materi tentang hafalan ayat-ayat Al Quran tidak hanya diajarkan di jam pelajaran PAI, namun diajarkan secara rutin di sekolah dengan didampingi guru khusus hafalan Al Quran.

Kedua, materi fiqih. Adapun materi fiqih yang terintegratif adalah shalat dhuha dan shalat dzuhur serta ashar di sekolah. Dalam kurikulum PAI, disebutkan tentang adanya materi-materi tentang shalat. Di SD Plus Tahfizhul Quran (PTQ) Annida ini, pembelajaran materi tentang shalat dhuha tidak hanya diajarkan di jam pelajaran PAI, namun diajarkan dengan praktik langsung yang dilakukan setiap mengawali kegiatan pembelajaran di sekolah setiap pagi.

Materi integratif langsung selanjutnya adalah shalat dzuhur dan ashar secara berjamaah. Dalam kurikulum PAI, disebutkan tentang adanya materi-materi tentang shalat lima waktu serta disunahkan untuk berjamaah. Di SD Plus Tahfizhul Quran (PTQ) Annida ini, pembelajaran materi tentang shalat lima waktu tidak hanya diajarkan di jam pelajaran PAI, namun diajarkan dengan praktik langsung shalat dhuhur dan ashar berjamaah yang dilakukan setiap hari sekolah dengan didampingi guru.

Ketiga, materi akhlak. Dalam kurikulum PAI, disebutkan tentang adanya materi-materi tentang akhlak dan ajaran-ajaran untuk hidup bersosial di masyarakat seperti toleransi, bersimpati, hormat kepada orang tua, hormat kepada guru, tolong menolong, dan lain sebagainya. Di SD Plus Tahfizhul Quran (PTQ) Annida, pembelajaran tentang akhlak ini tidak hanya diajarkan di kelas saat jam pelajaran PAI, namun dilakukan dalam sikap keseharian di sekolah. Lebih dalam lagi, terkait dengan penanaman akhlak ini, sekolah menjalin kerjasama dengan orang tua sebagai wujud kepedulian bersama untuk mendidik dan mengarahkan putra-putrinya terkait dengan akhlak.

Terkait dengan bentuk kerjasama integratif antara sekolah dengan orang tua wali murid, SD Plus Tahfizhul Quran (PTQ) Annida membuat program berupa lembar pemantauan siswa di rumah. Lembar pemantauan merupakan program yang dibuat dalam rangka memantau pengamalan siswa kaitannya dengan pembelajaran PAI. Beberapa materi dan pengamalan ibadah hal yang menjadi isi dari lembar pemantauan ini adalah materi tentang ibadah yang meliputi ibadah shalat, mengaji Al Quran, dan amal ibadah lainnya.

Secara ringkas, strategi pembelajaran PAI yang integratif bisa dilihat di dalam tabel berikut:

Tabel 1. Pembelajaran PAI Integratif

\begin{tabular}{|c|c|c|}
\hline $\begin{array}{l}\text { Aspek } \\
\text { Materi }\end{array}$ & $\begin{array}{c}\text { Program di } \\
\text { sekolah }\end{array}$ & $\begin{array}{c}\text { Program di luar } \\
\text { sekolah }\end{array}$ \\
\hline Al-Qur'an & $\begin{array}{l}\text { BTAQ dan hafalan } \\
\text { Al-Qur'an }\end{array}$ & $\begin{array}{c}\text { Kerjasama } \\
\text { dengan orang }\end{array}$ \\
\hline Fiqih & $\begin{array}{l}\text { Pembiasaan shalat } \\
\text { di sekolah }\end{array}$ & $\begin{array}{l}\text { tua tentang } \\
\text { pelaksanaan }\end{array}$ \\
\hline Akhlak & $\begin{array}{l}\text { Pembiasaan akhlak } \\
\text { terpuji di sekoolah }\end{array}$ & $\begin{array}{l}\text { program di } \\
\text { rumah }\end{array}$ \\
\hline
\end{tabular}


Program pembelajaran PAI secara integratif ini terlaksana sejak sebelum pandemi sampai di masa pandemi covid19 seperti saat ini. Hasil dari program integratif ini baik integratif langsung di sekolah ataupun integratif dengan orang tua di rumah bisa dikatakan berhasil. Hal ini dibuktikan dengan adanya hasil rekap lembar pemantauan siswa bahwa: 1) Lebih dari 75\% anak-anak melaksanakan shalat dengan tertib. 2) Anak-anak tidak hanya melaksanakan shalat wajib, tapi juga pembiasaan shalat sunah. 3) Anakanak juga memiliki kebiasaan untuk melaksanakan shalat dengan berjamaah. 4) Anak-anak memiliki hafalan lebih banyak karena sekolah memiliki program khusus yaitu mengaji dan menghafalkan Al-Qur'an. 5) Pembiasaan positif anak saat membantu mengerjakan tugas-tugas orang tua di rumah. 6) Pembiasaan anak dalam menolong sesama dan bersikap empati serta simpati.

Hasil positif atas capaian siswa ini merupakan hasil dari proses pendidikan yang terlaksana atas kerja sama antara sekolah dengan orang tua. Hal ini sesuai dengan yang disampaikan Irwn bahwa dalam proses pendidikan, dibutuhkan adanya suatu pembelajaran yang integratif antara guru, peranan orang tua dan masyarakat, yaitu adanya suatu kerjasama antara guru, orang tua dan masyarakat yang sesuai dengan perannya masing-masing (Irwan, 2020:55-68).

Selanjutnya, yang menjadi perbedaan antara pelaksanaan pembelajaran PAI secara integratif saat sebelum pandemi covid-19 dengan pembelajaran saat masa pandemi covid-19 ini terletak pada adanya kendala yang terjadi. Adapun yang menjadi kendala dalam pelaksanaan pembelajaran PAI secara intergratif di masa pandemi ini yaitu: (1) pembelajaran PAI di sekolah tidak terlaksana karena anak belajar dari rumah. Oleh karenanya, guru di sekolah tidak bisa memantau sepenuhnya terkait program yang direncanakan oleh sekolah dengan yang dilaksanakan oleh siswa di rumah; (2) siswa cenderung kurang semangat dalam melaksanakan tugas di rumah. Ini berlaku untuk semua mata pelajaran, termasuknya PAI. Dampaknya adalah prestasi siswa yang menurun dan target yang kurang tercapai maksimal. Hal ini sesuai dengan penelitian dari Asmuni bahwa salah satu problematika pembelajaran jarak jauh di masa pandemi Covid-19 ini adalah siswa kurang aktif mengikuti pembelajaran (Asmuni, 2020:281-288). Hal ini terjadi karena siswa tidak bisa mendapatkan instruksi secara langsung dari gurunya; (3) Komunikasi antara guru/ sekolah dengan orang tua kurang maksimal karena komunikasi hanya dilaksanakan lewat media komunikasi seperti Whatsapp.

Berkenaan dengan permasalahan tersebut, pihak sekolah berupaya untuk memberikan solusi terbaik, di antaranya adalah: (1) menyederhanakan instruksi pembelajaran yang dilakukan oleh guru; (2) menjalin komunikasi sebaik mungkin antara sekolah dengan orang tua; dan (3) memberikan apresiasi lebih kepada siswa untuk meningkatkan semangat siswa.

\section{PENUTUP}

\section{Simpulan}

Dari penelitian ini disimpulkan bahwa pembelajaran PAI secara integratif langsung adalah bersatunya antara materi pelajaran dengan kegiatan secara keseluruhan di sekolah serta kerjasama sekolah dengan orang tua dalam upaya melaksanakan pengamalan-pengamalan PAI secara nyata di luar sekolah. Pelaksanaan program integratif ini adalah meliputi program yang ada di sekolah dan kerjasama dengan orang tua di rumah. Aspek dari pembelajaran PAI secara integratif langsung di SD Plus Tahfizhul Quran (PTQ) ANNIDA meliputi materi AlQur'an, fiqih dan akhlak. Materi Al-Qur'an meliputi pembiasaan Baca Tulis Al-Quran dan menghafalkan Al-Quran. Materi fiqih meliputi shalat dhuha, shalat dzuhur dan ashar secara berjamaah. Sedangkan materi akhlak adalah pembiasaan toleransi, bersimpati, hormat kepada orang tua, hormat kepada guru, tolong menolong, dan lain sebagainya. Hasil dari 
program integratif ini adalah anak-anak terbiasa dalam melakukan kegiatan positif yang meliputi kegiatan ibadah dan akhlak. Hasil dari program pembelajaran PAI integratif ini adalah lebih dari 75\% anak-anak melaksanakan shalat dengan tertib, pembiasaan shalat sunah dan berjama'ah, kemampuan mengaji dan hafalan Al-Qur'an, pembiasaan positif di rumah, serta sikap empati dan simpati dari anak-anak. Materi integratif ini sudah dilaksanakan sejak sebelum dan pada saat pandemi Covid-19 ini. Yang membedakan adalah adanya kendala yang muncul pada saat masa pandemi Covid-19. Kendala yang muncul adalah guru tidak bisa memantau secara penuh karena siswa tidak berangkat ke sekolah, siswa kurang semangat, dan komunikasi yang kurang maksimal. Solusi yang dihadirkan adalah menyederhanakan instruksi pembelajaran oleh guru, menjalin komunikasi sebaik mungkin, dan pemberian apresiasi kepada siswa agar tambah semangat.

Dari hasil penelitian ini, peneliti memberikan beberapa saran, yaitu (1) kepada SD Plus Tahfizhul Quran (PTQ) Annida agar memperluas materi PAI yang dilaksanakan secara integratif semisal pada materi hadits, akidah, dan bahasa Arab; (2) kepada peneliti selanjutnya bisa memperdalam kajian penelitian dengan tema yang sama namun dengan integrasi pada aspek yang berbeda.

\section{DAFTAR PUSTAKA}

Abdullah, M. Amin. (2012). Islamic Studies di Perguruan Tinggi; Pendekatan IntegratifInterkonektif. Yogyakarta: Pustaka Pelajar.

Asmuni. (2020). Problematika Pembelajaran Daring di Masa Pandemi Covid-19 dan Solusi Pemecahannya. Jurnal Paedagogy 7(4). https://doi.org/10.33394/ip.v7i4.2941

Az-Zahida, Wida. (2009) Mentoring Fun, Solo: Indiva Media Kreasi

Baedowi, Ahmad, dkk (2015) Potret Pendidikan Kita, Jakarta: Pustaka Alfabet

Irwan. (2020). PENGEMBANGAN PEMBELAJARAN PAI YANG INTEGRATIF: Antara Guru PAI, Orang Tua dan Masyarakat. Jurnal Tajdid 4(1).

Hidayat, Muslih. (2014) Pendekatan Integratif-Interkonektif: Tinjauan Paradigmatik dan Implementatif dalam Pembelajaran Pendidikan Agama Islam. Ta'dib 14(2)

Hidayati, Wiji. (2015) Muatan Keilmuan Integrasi Pendidikan Agama Islam dan Budi Pekerti. Telaah Kurikulum 2013 Jenjang SMA. Jurnal Pendidikan Agama Islam 12(1).

Machali Imam. (2017) Pendekatan Integrasi dalam Kajian Manajemen dan Kebijakan Pendidikan Islam. Jurnal El Tarbawi 8(1). http://dx.doi.org/10.20885/ tarbawi.vol8.iss1.art3).

Ms, Rohmad. 2015. Pendekatan Integratif Pembelajaran Pendidikan Agama Islam (PAI) di Sekolah Pada Abad Informasi. Jurnal Inovatif 1(1).

Nata, Abuddin. (2007) Manajemen Pendidikan, Jakarta: Kencana

Roqib, Moh. (2009). Ilmu Pendidikan Islam: Pengembangan Pendidikan Integratif di Sekolah, Keluarga, dan Masyarakat. Yogyakarta: LKIS.

Ruhama, Ulfatur. (2016) Integrasi Pendidikan Agama Islam dan Ekstrakurikuler Pramuka dalam Membentuk Kepribadian Siswa. JOIES: Journal of Islamic Education Studies $1(2)$. 
Sabiq, Ahmad Fikri. (2017). Pendekatan Saintifik dalam Pembelajaran Pendidikan Agama Islam. Salatiga: Linsser Media.

SD PTQ Annida. (2017). Profil SD Plus Tahfizhul Quran (PTQ) ANNIDA.

Suryadi, Rudi Ahmad. (2016). Visi dan Paradigma Pendidikan Agama Islam (PAI): Kualitas, Integratif dan Kompetitif. Edukasi 4(2): 253-276

Wage dan Sulaeman, A. (2016). Pemberdayaan Pendidikan Agama Islam di Sekolah dan Perguruan Tinggi Umum. ISLAMADINA 17(2): 31-40. 